Jurnal Teknik Kimia Indonesia Vol. 8 No. 1 April 2009, 6-11

\title{
PEMANFAATAN EMISI GAS METANA DARI STASIUN KOMPRESOR SISTEM PERPIPAAN GAS ALAM SEBAGAI SUMBER ENERGI TERMAL
}

\author{
Yogi Wibisono Budhi*, Mohammad Effendy \\ Program Studi Teknik Kimia, Fakultas Teknologi Industri \\ Institut Teknologi Bandung \\ Jalan Ganesha 10 Bandung 40132 \\ Email: Y.Wibisono@che itb ac.id
}

\begin{abstract}
Abstrak
Emisi gas $\mathrm{CH}_{4}$ ke atmosfer dapat menyebabkan pengaruh pemanasan global 21 kali lebih tinggi dibandingkan gas $\mathrm{CO}_{2}$. Salah satu strategi untuk mengurangi dampak tersebut adalah dengan mengkonversi gas $\mathrm{CH}_{4}$ menjadi $\mathrm{CO}_{2}$ dalam Reaktor Aliran Bolak-Balik (RABB). RABB adalah piranti yang tepat untuk mengolah gas yang berkonsentrasi sangat kecil (0,1-1 \%-v). Reaksi pembakaran $\mathrm{CH}_{4}$ bersifat eksotermis dengan $\Delta \mathrm{T}_{\text {adiabatik }}$ berkisar antara $10-200^{\circ} \mathrm{C}$ (konsentrasi $0,1-1 \%-\mathrm{v}$ ), sehingga panas reaksinya dapat dimanfaatkan sebagai sumber energi termal. RABB memiliki kemampuan dalam mengendalikan pergerakan panas di dalam reaktor, menyimpan panas, dan memberikannya kembali untuk memanaskan umpan yang bertemperatur rendah. Makalah ini menyampaikan hasil kajian tentang pengaruh pengambilan panas hasil reaksi pembakaran gas $\mathrm{CH}_{4}$ sebagai sumber energi termal terhadap kinerja RABB. Metodologi yang digunakan adalah dengan simulasi komputer. Untuk laju alir umpan sebesar $0,22 \mathrm{~L} / \mathrm{s}$, panas optimum yang dapat dimanfaatkan adalah $43 \mathrm{~kJ} / \mathrm{m}^{3}$.s (efisiensi pemulihan panas 50,4\%) dan dibutuhkan laju alir udara sebesar 92,9 g/s untuk mengekstrak panas.
\end{abstract}

Kata kunci: Reaktor aliran bolak-balik, pembakaran katalitik metana, pemodelan, simulasi efek rumah kaca, sistem perpipaan gas

\begin{abstract}
Emission of $\mathrm{CH}_{4}$ gas to the atmosphere may result in a global warming effect 21 times larger than that of $\mathrm{CO}_{2}$. One of the strategies to reduce this impact is to convert $\mathrm{CH}_{4}$ to $\mathrm{CO}_{2}$ in a Reverse Flow Reactor (RFR). RFR is a suitable apparatus to process gases with very low concentrations $(0.1-1 \%-\mathrm{v})$. The $\mathrm{CH}_{4}$ combustion reaction is exothermic, with a $\Delta \mathrm{T}_{\text {adiabatic }}$ between $10-200{ }^{\circ} \mathrm{C}$ (at a $0.1-1 \%-\mathrm{v}$ concentration), and therefore its heat of reaction may be used as a thermal energy source. RFR is capable of controlling heat transfer in the reactor, storing heat, and releasing it to heat low-temperature feeds. This paper presents the results of a study on the effect of the removal of heat generated by $\mathrm{CH}_{4}$ combustion as thermal energy source on the performance of RFR. The methodology in this study involved computer simulations. For a feed flowrate of $0.22 \mathrm{~L} / \mathrm{s}$, the optimum rate of heat that can be recovered was $43 \mathrm{~kJ} / \mathrm{m}^{3} \cdot \mathrm{s}$ (heat recovery efficiency of $50.4 \%$ ). An air flowrate of $92.9 \mathrm{~g} / \mathrm{s}$ was required to extract the heat.
\end{abstract}

Keyword: Reverse flow reactor, methane catalytic combustion, modeling, green house effect simulation, gas piping system.

*korespondensi 


\section{Pendahuluan}

Pengaruh emisi gas $\mathrm{CH}_{4}$ terhadap pemanasan global dapat mencapai 21 kali lebih berbahaya dibandingkan $\mathrm{CO}_{2}$. Emisi gas $\mathrm{CH}_{4}$ terutama ditimbulkan oleh sektor agrikultur (44\%), pembakaran biomassa (22\%), penambangan batubara $(12 \%)$, dan industri minyak dan gas (15\%), yang menghasilkan $\pm 15 \mathrm{Mt} /$ tahun. Dalam industri minyak dan gas, pengaruh efek pemanasan global setara dengan $47 \mathrm{Mt} /$ tahun. Emisi gas $\mathrm{CH}_{4}$ dari sektor industri minyak dan gas dapat disebabkan oleh kebocoran di dalam jaringan pipa transmisi dan stasiun kompresor sistem perpipaan gas bumi. Sumber kebocoran dalam stasiun kompresor dapat berasal dari tiga tempat, yaitu reaksi pembakaran yang tidak sempurna pada mesin kompresor, kebocoran yang terjadi pada peralatan seperti valve dan flange, dan pada instrumen venting kompresor. Berdasarkan data dari Clearstone Engineering Ltd. (2008), setiap stasiun kompresor memiliki instrumen 5 kompresor (4 buah dengan daya $1650 \mathrm{hp}$ dan 1 buah dengan daya $1450 \mathrm{hp}$ ), dehidrator glikol, dan dua buah generator. Gas bumi biasanya digunakan sebagai bahan bakar untuk mengoperasikan instrumen di stasiun kompresor tersebut. Emisi gas $\mathrm{CH}_{4}$ yang ditimbulkan adalah sebesar 1330 ton/tahun yang terdiri dari 930 ton/tahun kebocoran di perpipaan (49 \% dari instrument venting kompresor, $36 \%$ dari ventilasi tangki penghasil air, 7\% akibat kebocoran, 7\% dari dehidrator glikol, 1\% dari sumber lain) dan 400 ton/tahun dari reaksi pembakaran tidak sempurna mesin.

Gas $\mathrm{CH}_{4}$ yang terbuang ke lingkungan merupakan sumber gas rumah kaca. Pengaruh pemanasan global yang disebabkan oleh gas $\mathrm{CH}_{4}$ bisa dikurangi dengan cara mengubah gas $\mathrm{CH}_{4}$ menjadi gas $\mathrm{CO}_{2}$. Konversi gas $\mathrm{CH}_{4}$ menjadi gas $\mathrm{CO}_{2}$ merupakan reaksi pembakaran yang bersifat eksotermis. Panas hasil reaksi pembakaran gas $\mathrm{CH}_{4}$ dapat digunakan sebagi sumber energi termal.

Sapoundjiev dan Aube (1999) telah berhasil mengurangi pengaruh pemanasan global akibat gas $\mathrm{CH}_{4}$ yang dihasilkan pada tambang baubara dengan mengubah gas $\mathrm{CH}_{4}$ menjadi gas $\mathrm{CO}_{2}$ menggunakan reaktor katalitik aliran bolak-balik. Panas hasil pembakaran gas $\mathrm{CH}_{4}$ diambil dengan menggunakan udara Pada konsentrasi gas $\mathrm{CH}_{4}$ $0,3 \%(\mathrm{v} / \mathrm{v})$, panas yang dapat diambil sebesar $52 \%$ dari panas yang dihasilkan oleh reaksi pembakaran $\mathrm{CH}_{4}$. Temperatur udara keluar stabil pada $700{ }^{\circ} \mathrm{C}$. Konsentrasi gas $\mathrm{CH}_{4}$ di dalam udara yang semakin meningkat mengakibatkan efisiensi pemulihan panas juga semakin besar. Cittadini dkk. (2002) mempelajari pengaruh parameter desain (panjang unggun, switching time, dan fraksi dari unggun) dan parameter operasi (konsentrasi masuk dan laju alir) pada pengoperasian reaktor aliran bolak-balik. Pemilihan panjang unggun, waktu periodik, dan fraksi dari material inert adalah sangat penting untuk dikaji. Tujuan penelitian ini adalah untuk mengamati pengaruh pengambilan panas hasil reaksi katalitik pembakaran gas $\mathrm{CH}_{4}$ sebagai sumber energi termal terhadap kinerja reaktor katalitik aliran bolak-balik.

\section{Metodologi}

Reaksi pembakaran gas $\mathrm{CH}_{4}$ dengan kadar yang kecil hanya dapat terjadi dengan bantuan katalis agar temperatur reaksi tidak terlalu tinggi. Konversi $\mathrm{CH}_{4}$ menjadi gas $\mathrm{CO}_{2}$ merupakan reaksi yang bersifat eksotermik. Panas yang dihasilkan akan digunakan sebagai sumber energi termal. Untuk mendapatkan jumlah panas yang besar, konfigurasi reaktor unggun tetap ditunjukkan pada Gambar 1. Bagian reaktor yang berisi inert berfungsi sebagai penyimpan panas (recuperative) dan diletakkan di bagian ujung-ujung reaktor. Proses penyimpanan panas dilakukan dengan cara mengubah arah aliran secara periodik (reverse flow). Panas yang tersimpan di dalam reaktor bagian inert akan digunakan untuk memanaskan umpan yang masuk ke reaktor dengan temperatur lingkungan. Penukar panas di bagian tengah reaktor digunakan untuk mengambil panas

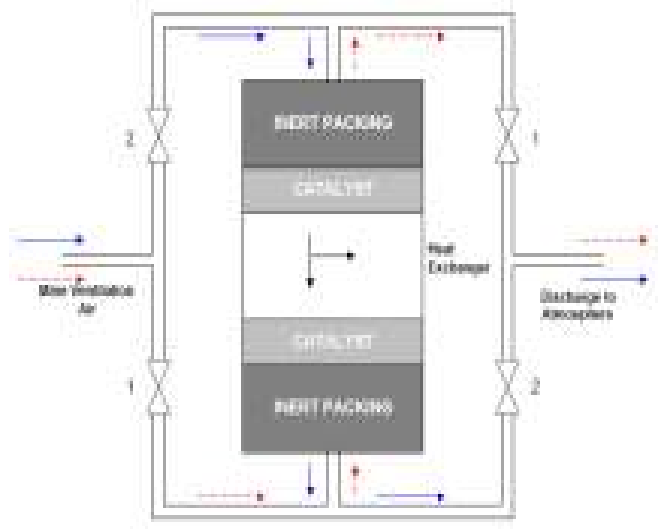

Gambar 1. Konfigurasi reaktor aliran bolak-balik 
Tabel 1. Model pseudo-homogenous RABB untuk reaksi katalitik $\mathrm{CH}_{\mathbf{4}}$

$\left(\varepsilon_{\mathrm{g}} \rho_{\mathrm{g}} \mathrm{c}_{\mathrm{g}}+\varepsilon_{\mathrm{g}} \rho_{\mathrm{g}} \mathrm{c}_{\mathrm{g}}\right) \frac{\partial \mathrm{T}}{\partial \mathrm{t}}=\lambda_{\mathrm{ef}} \frac{\partial^{2} \mathrm{~T}}{\partial \mathrm{l}^{2}}-\rho_{\mathrm{g}}^{\mathrm{o}} \mathrm{c}_{\mathrm{g}} \mathrm{U}(\mathrm{t}) \frac{\partial \mathrm{T}}{\partial \mathrm{l}}+\mathrm{r}_{\mathrm{CH}_{4}} \Delta \mathrm{H}_{\mathrm{CH}_{4}}-\mathrm{Q}_{1}-\mathrm{Q}_{\text {heater }}$
$\frac{\partial \mathrm{T}_{\text {udara }}}{\partial \mathrm{t}}=\left(\frac{\mathrm{h}_{\text {udara }} \mathrm{A}_{\text {heater }}}{\mathrm{m}_{\text {udara }} \mathrm{C}_{\mathrm{p} \text {,udara }}}\right)\left(\mathrm{T}-\mathrm{T}_{\text {udara }}\right)$
$\frac{\partial \mathrm{C}_{\mathrm{CH}_{4}}}{\partial \mathrm{t}}=-\mathrm{U}(\mathrm{t}) \frac{\partial \mathrm{C}_{\mathrm{CH}_{4}}}{\partial \mathrm{x}}-\mathrm{r}_{\mathrm{CH}_{4}}$
$\frac{\partial \mathrm{C}_{\mathrm{O}_{2}}}{\partial \mathrm{t}}=-\mathrm{U}(\mathrm{t}) \frac{\partial \mathrm{C}_{\mathrm{O}_{2}}}{\partial \mathrm{x}}-2 \mathrm{r}_{\mathrm{CH}_{4}}$
$\frac{\partial \mathrm{C}_{\mathrm{H}_{2} \mathrm{O}}}{\partial \mathrm{t}}=-\mathrm{U}(\mathrm{t}) \frac{\partial \mathrm{C}_{\mathrm{H}_{2} \mathrm{O}}}{\partial \mathrm{x}}+2 \mathrm{r}_{\mathrm{CH}_{4}}$
$\frac{\partial \mathrm{C}_{\mathrm{CO}_{2}}}{\partial \mathrm{t}}=-\mathrm{U}(\mathrm{t}) \frac{\partial \mathrm{C}_{\mathrm{CO}_{2}}}{\partial \mathrm{x}}+\mathrm{r}_{\mathrm{CH}_{4}}$
$\frac{\partial \mathrm{C}_{\mathrm{N}_{2}}}{\partial \mathrm{t}}=-\mathrm{U}(\mathrm{t}) \frac{\partial \mathrm{C}_{\mathrm{N}_{2}}}{\partial \mathrm{x}}$

Tabel 2. Dimensi reaktor

\begin{tabular}{ll}
\hline \multicolumn{1}{c}{ Dimensi } & \multicolumn{1}{c}{ Uraian } \\
\hline Diameter reaktor & $27 \mathrm{~mm}$ \\
Panjang total reaktor & $960 \mathrm{~mm}$ \\
Panjang zona katalis & $2 \times 100 \mathrm{~mm}$ \\
Panjang zona inert & $2 \times 330 \mathrm{~mm}$ \\
Panjang zona heat & $100 \mathrm{~mm}$ \\
exchanger & \\
Material reaktor & Stainless Steel \\
& SS 304 L \\
\hline
\end{tabular}

hasil reaksi pembakaran $\mathrm{CH}_{4}$ di bagian katalis. Di dalam bagian ini, panas yang terambil akan digunakan sebagai sumber energi termal.

Pemodelan RABB merupakan langkah awal dalam bagian simulasi computer. Perangkat lunak yang digunakan adalah FlexPDE versi 3. Pemodelan dan simulasi RABB untuk neraca massa dan panas menggunakan model pseudo-homogeneous satu dimensi. Neraca momentum tidak dilibatkan dalam pemodelan karena hilang tekan untuk reaktor berskala laboratorium dirancang sekecil mungkin. Persamaan neraca massa dan energi RABB untuk reaksi katalitik $\mathrm{CH}_{4}$ dapat dilihat dalam Tabel 1. Model reaktor terdiri dari 5 zona, yaitu zona inert, zona katalis, zona heat exchanger, zona katalis, dan zona inert (Gambar 1). Panjang zona inert di sebelah kiri/atas sama dengan. panjang zona inert di sebelah kanan/bawah dari zona katalis. Data lengkap dimensi reaktor dapat dilihat pada Tabel 2 .
Panas yang hilang ke lingkungan dimodelkan dalam persamaan 8 ,

$$
Q_{1}=\frac{2 \Pi L\left(T-T_{\text {udara }}\right)}{\frac{\ln \left(r_{2} / r_{1}\right)}{K}+\frac{1}{r_{2} h_{0}}}
$$

di mana $h_{o}$ adalah koefisien perpindahan panas keseluruhan dengan nilai sebesar 0,18 $\mathrm{Wm}^{-2} \mathrm{~K}^{-1}$ (Cittadini, 2001). Panas hasil reaksi pembakaran katalitik $\mathrm{CH}_{4}$ yang dapat diambil di penukar panas mengikuti persamaan 9 .

$Q_{\text {heater }}=m_{\text {udara }} C_{p, \text { udara }}\left(T_{\text {udara }}-T_{\text {udara }}^{0}\right)$

Reaksi pembakaran katalitik $\mathrm{CH}_{4}$ yang terjadi di dalam RABB dimodelkan sebagai berikut:

$\mathrm{CH}_{4}+2 \mathrm{O}_{2} \rightarrow \mathrm{CO}_{2}+2 \mathrm{H}_{2} \mathrm{O}$

Sedangkan model untuk laju reaksi diperoleh dari peneliti pendahulu. Laju reaksi pembakaran $\mathrm{CH}_{4}$ menggunakan katalis $10 \%$ $\mathrm{PdO} / \mathrm{ZrO}_{2}$ adalah sebagai berikut (Ibashi dkk., 2003):

$$
r_{\mathrm{CH}_{4}}=K_{\mathrm{CH}_{4}}\left(\frac{w_{\text {katalis }}}{V_{\text {reaktor }}-V_{\text {katalis }}}\right)\left(C_{\mathrm{CH}_{4}} R T\right)\left(\frac{1}{C_{\mathrm{H}_{2} \mathrm{O}}}\right)\left(\frac{1}{C_{\mathrm{CO}_{2}} R T}\right)
$$

Kondisi operasi dan parameter reaksi untuk menyelesaikan model dapat dilihat pada Tabel 3. 


\begin{tabular}{|c|c|c|c|}
\hline \multicolumn{4}{|c|}{$\begin{array}{c}\text { Tabel 3. Kondisi operasi dan } \\
\text { parameter reaksi }\end{array}$} \\
\hline Reaksi & Simbol & Nilai & Satuan \\
\hline $\begin{array}{l}\mathrm{CH}_{4}+2 \mathrm{O}_{2} \\
\rightarrow \mathrm{CO}_{2}+\mathrm{H}_{2} \mathrm{O}\end{array}$ & $\begin{array}{c}k_{0, \mathrm{CH}_{4}} \\
E_{C H_{4}} \\
\Delta H_{r, C_{7 H_{8}}}\end{array}$ & $\begin{array}{c}2,22 \cdot 10^{-2} \\
108 \\
802\end{array}$ & $\begin{array}{c}\text { Mol.Kgcat }{ }^{-1} \cdot \mathrm{s}^{-1} \\
\text { kJ.mol-1 } \\
\text { kJ.mol-1 }\end{array}$ \\
\hline $\begin{array}{l}\text { Material } \\
\text { inert: Dolomit }\end{array}$ & $\begin{array}{c}\mathrm{C}_{\mathrm{p}} \\
\mathrm{K} \\
\rho \\
\mathrm{d}\end{array}$ & $\begin{array}{c}0,920 \\
5 \\
3500 \\
0,003\end{array}$ & $\begin{array}{c}\mathrm{kJ} \cdot \mathrm{kg}^{-1} \cdot \mathrm{K}^{-1} \\
\mathrm{~W} \cdot \mathrm{m}^{-1} \mathrm{k}^{-1} \\
\mathrm{Kg} \cdot \mathrm{m}^{-3} \\
\mathrm{~mm}\end{array}$ \\
\hline $\begin{array}{l}\text { Material } \\
\text { katalis: } 10 \% \\
\text { PdO/ZrO }\end{array}$ & $\begin{array}{l}C_{p} \\
K \\
\rho \\
d\end{array}$ & $\begin{array}{c}1,050 \\
18 \\
3720 \\
0,003\end{array}$ & $\begin{array}{c}\mathrm{kJ} \cdot \mathrm{kg}^{-1} \cdot \mathrm{K}^{-1} \\
\mathrm{~W} \cdot \mathrm{m}^{-1} \mathrm{k}^{-1} \\
\mathrm{Kg} \cdot \mathrm{m}^{-3} \\
\mathrm{~mm}\end{array}$ \\
\hline \multicolumn{4}{|c|}{ Kondisi operasi } \\
\hline $\begin{array}{l}\text { Switching time } \\
\text { Waktu tinggal } \\
\text { Temp. umpan } \\
\text { Temp.reaktor } \\
\text { Tekanan }\end{array}$ & $\begin{array}{c}\mathrm{ST} \\
\mathrm{t} \\
\mathrm{T}_{0} \\
\mathrm{~T}_{\text {awal }} \\
\mathrm{P}\end{array}$ & $\begin{array}{c}60 \\
1 \\
303 \\
773 \\
1,5\end{array}$ & $\begin{array}{c}\mathrm{S} \\
\mathrm{S} \\
\mathrm{K} \\
\mathrm{K} \\
\mathrm{atm}\end{array}$ \\
\hline \multicolumn{4}{|c|}{ Komposisi gas umpan } \\
\hline $\begin{array}{l}\text { Laju } \\
\text { volumetrik gas }\end{array}$ & $q$ & $2,2 \cdot 10^{-4}$ & $\mathrm{~m}^{3} \cdot \mathrm{s}^{-1}$ \\
\hline Kadar $\mathrm{CH}_{4}$ & $\begin{array}{l}\mathrm{OCH}_{4} \\
(\mathrm{v} / \mathrm{v})\end{array}$ & 1 & - \\
\hline Kadar $\mathrm{O}_{2}$ & $\begin{array}{l}\% \mathrm{O}_{2} \\
(\mathrm{v} / \mathrm{v})\end{array}$ & 20 & - \\
\hline Kadar $\mathrm{N}_{2}$ & $\begin{array}{l}\% \mathrm{~N}_{2} \\
(\mathrm{v} / \mathrm{v})\end{array}$ & balance & - \\
\hline
\end{tabular}

\section{Hasil dan Pembahasan}

Di dalam penelitian ini, target yang ingin dicapai untuk mengetahui besarnya panas yang dapat dimanfaatkan sebagai sumber energi termal dengan memperhatikan batas bawah temperatur reaksi agar tidak padam (extinction). Metode pengambilan panas menggunakan shell and tube one pass. Skema shell and tube one pass ditunjukkan pada Gambar 2. Udara dialirkan pada bagian shell dengan waktu tinggal 0,6 detik. Aliran panas akan berpindah dan bagian tube (campuran gas) menuju bagian shell (udara) melewati dinding reaktor bagian dalam. Pembalikan temperatur di bagian shell mengikuti persamaan 2. Panas hasil reaksi pembakaran yang dapat diambil oleh udara dipengaruhi oleh laju alir massa udara di bagian shell. Variasi massa udara yang mengalir melalui shell dilakukan untuk mengetahui kuantitas panas yang dapat diambil dengan pertimbangan bahwa reaksi pembakaran $\mathrm{CH}_{4}$ tetap berlangsung.

Variasi laju alir massa udara di bagian shell menyebabkan perbedaan profil temperatur di sepanjang reaktor. Perbedaan profil temperatur di sepanjang reaktor

disebabkan jumlah panas yang dapat diambil oleh udara pada bagian shell berbeda-beda. Profil temperatur di sepanjang reaktor tiap saat ditunjukkan pada Gambar 3. Dalam proses pengoperasian reaktor katalitik aliran bolak-balik, reaktor dipanaskan sampai mencapai kondisi temperatur titik bakar $\mathrm{CH}_{4}$ $(773 \mathrm{~K})$, kemudian campuran gas $\mathrm{CH}_{4}$ dalam udara pada suhu $303 \mathrm{~K}$ dialirkan ke dalam reaktor.

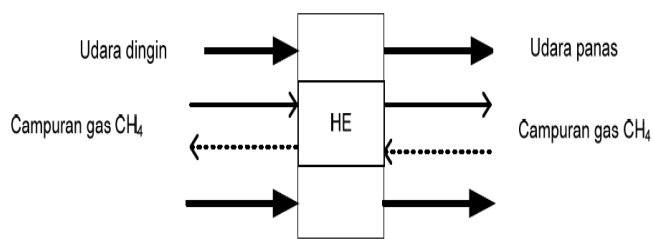

Gambar 2. Skema shell and tube one pass

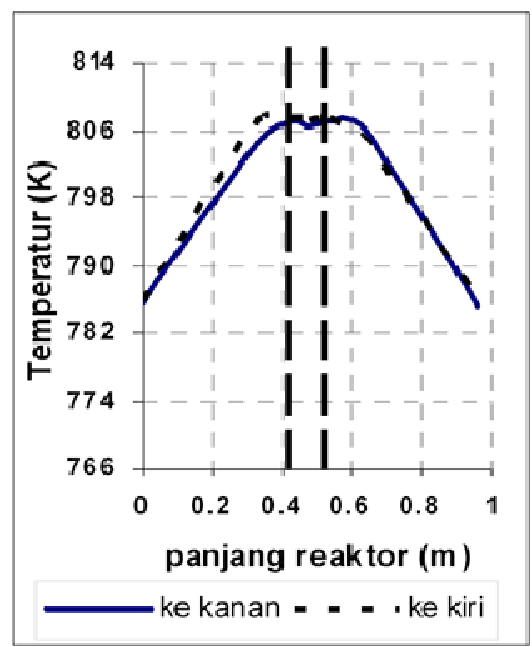

(a) $M_{\text {udara }}=5,7 \mathrm{gram} / \mathrm{s}$

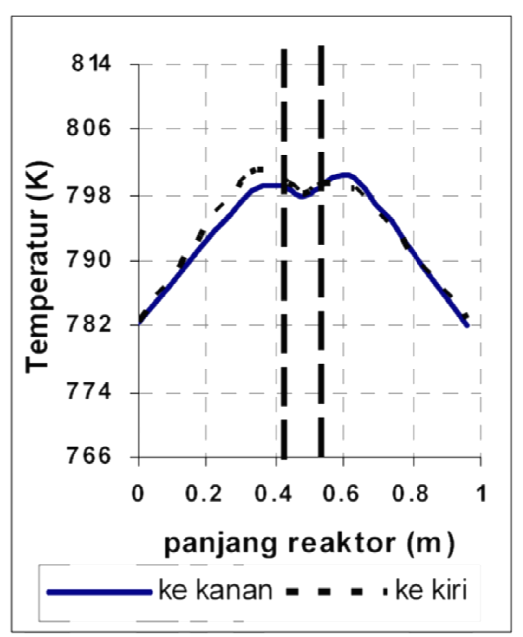

(b) $M_{\text {udara }}=23,1 \mathrm{gram} / \mathrm{s}$ 


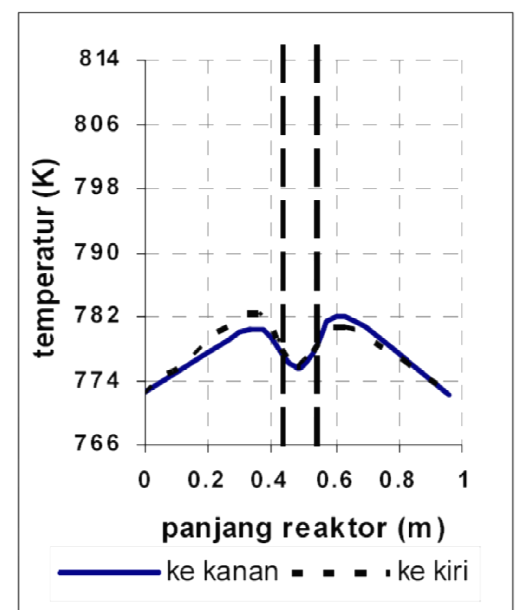

(c) $M_{\text {udara }}=52,2 \mathrm{gram} / \mathrm{s}$

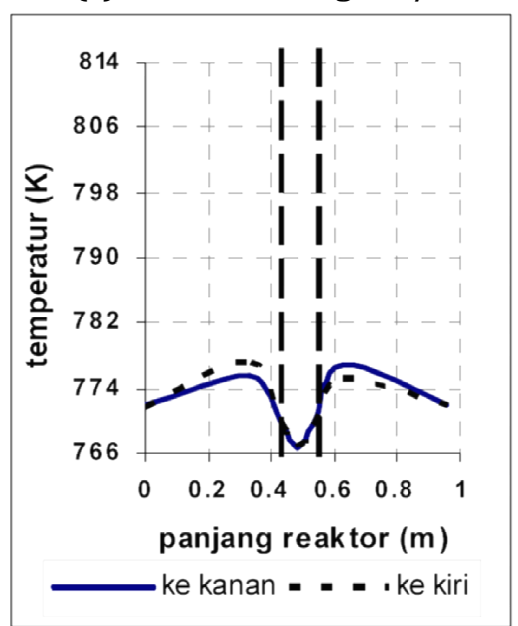

(d) $M_{\text {udara }}=92,9 \mathrm{gram} / \mathrm{s}$

Gambar 3. Profil temperatur reaktor aliran bolak-balik sepanjang reaktor sesaat setelah aliran dibalik untuk variasi laju alir massa udara (a sampai d) dengan $\mathrm{T}_{\text {umpan }}=-303 \mathrm{~K}$, laju alir umpan $\mathrm{CH}_{4} 1 \%$. $T_{\text {awal reactor }}=773 \mathrm{~K}$, dan $\tau=1 \mathrm{~s}$.

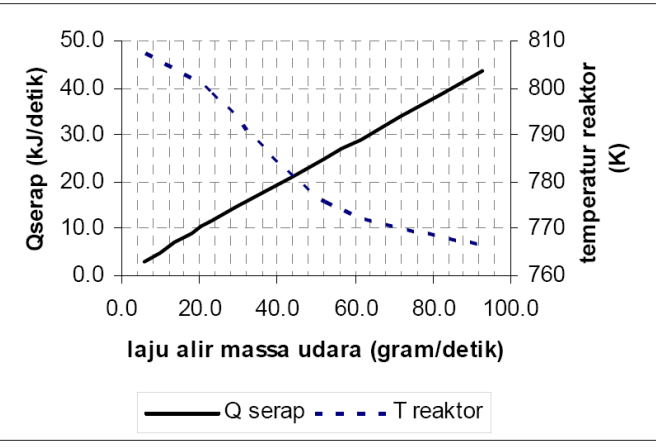

Gambar 4. Pengaruh penambahan laju alir massa udara terhadap $Q$ yang diserap dan $T$ reaktor pada bagian tengah $\mathrm{HE}$.
Besarnya laju alir massa udara dalam mengekstrak panas dibatasi oleh temperatur reaktor zona katalis. Panas yang hilang sepanjang reaktor cukup tinggi (akibat diserap oleh udara ataupun hilang ke lingkungan) akan mengakibatkan reaksi pembakaran tidak akan berjalan. Pengaruh kenaikan laju alir massa udara terhadap penurunan temperatur rata-rata di zona katalis ditunjukkan pada Gambar 5.

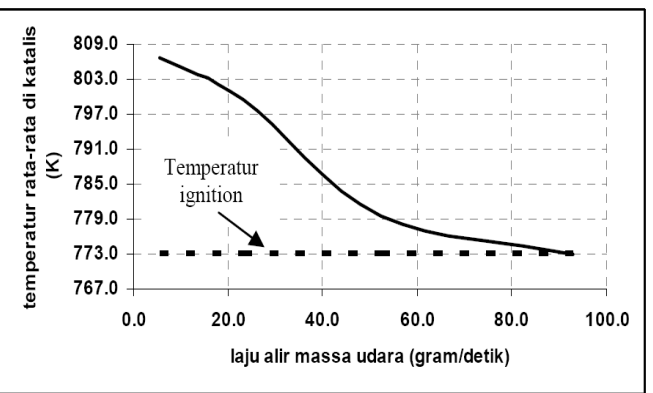

Gambar 5. Pengaruh kenaikan laju alir udara terhadap temperatur rata-rata di zona katalis

Dari Gambar 4 dan 5 dapat dinyatakan, pada laju alir massa udara 92,9 g/s merupakan titik optimum dalam pemanfaatan panas hasil reaksi pembakaran katalitik gas $\mathrm{CH}_{4}$. Panas reaksi pembakaran katalitik dapat dimanfaatkan adalah sebesar 43,5 kJ.s dengan efisiensi pemulihan panas sebesar 50,4\%. Perhitungan efisiensi pemulihan panas berdasarkan pada perbandingan panas yang dapat diambil oleh udara dengan panas hasil reaksi pembakaran gas $\mathrm{CH}_{4}$. Sisa panas yang terkandung dalam aliran gas digunakan untuk mempertahankan temperatur reaksi di zona katalis.

\section{Kesimpulan}

Pengembangan teknologi reaktor katalitik aliran bolak-balik untuk diaplikasikan pada proses pengurangan gas $\mathrm{CH}_{4}$ dan pemanfaatan panas hasil pembakaran pada stasiun kompresor sistem perpipaan gas alam merupakan solusi yang tepat untuk mengatasi persoalan pemanasan global dan penyediaan energi. Rancangan reaktor, khususnya yang terkait dengan proses pengambilan panas hasil reaksi pembakaran gas $\mathrm{CH}_{4}$, harus menjadi perhatian khusus. Hal ini terkait dengan kemungkinan reaksi tidak akan berjalan apabila pengambilan panas yang cukup besar, yang menyebabkan temperatur di dalam zona katalis berada di bawah temperatur ignition. 


\section{Ucapan Terima Kasih}

Penulis menyampaikan terima kasih kepada Ikatan Alumni Institut Teknologi Bandung (IA-ITB) yang telah memberikan bantuan dana penelitian dalam proyek Riset Internasional yang berjudul New Alternative Thermal Energy Production While Reducing Greenhouse Gas Emission from Coal Mine Flue Gas Using a Novel Technology of Reverse Flow Reactor untuk tahun 2008/2009.

\section{Daftar Notasi}

C konsentrasi [mol.m $\left.\mathrm{m}^{-3}\right]$

$c_{g} \quad$ kapasitas panas fase gas

[J.kg-1 $\mathrm{K}^{-1}$ ]

$c_{s} \quad$ kapasitas panas fase solid [J.kg-1 $\mathrm{K}^{-1}$ ]

$E \quad$ energi aktivasi [ $\left.\mathrm{m}^{3} \mathrm{~atm} \cdot \mathrm{mol}^{-1}\right]$

$h_{o} \quad$ koefisien perpindahan panas

konveksi [W $\left.\mathrm{m}^{-2} \mathrm{~K}^{-1}\right]$

$k_{o} \quad$ konstanta kecepatan reaksi $\left[\mathrm{m}^{3} \mathrm{~mol}^{-1} \mathrm{~s}^{-1}\right]$

$l \quad$ koordinat aksial [m]

$Q \quad$ laju alir panas keluar [J.detik ${ }^{-1}$ ]

$r \quad$ laju reaksi kimia [mol. $\mathrm{m}^{-3}$ detik $^{-1}$ ]

$T \quad$ temperatur $[\mathrm{K}]$

$t \quad$ Waktu [detik]

$U \quad$ kecepatan linier [m detik $\left.{ }^{-1}\right]$

$u \quad$ kecepatan linier mutlak [m.detik-1]

\section{Daftar Simbol}

$\Delta \mathrm{H} \quad$ panas reaksi [J.mole ${ }^{-1}$ ]

$\varepsilon_{\mathrm{g}} \quad$ fraksi gas di unggun tetap [-] $\varepsilon_{\mathrm{s}} \quad$ fraksi padat di unggun tetap [-]

$\rho_{\mathrm{g}} \quad$ massa jenis gas $\left[\mathrm{kg} \cdot \mathrm{m}^{-3}\right]$

$\rho_{\mathrm{s}} \quad$ massa jenis solid $\left[\mathrm{kg} \mathrm{m}^{-3}\right]$

$\lambda_{\text {eff }} \quad$ konduktifitas panas efektif [J.detik ${ }^{-1} \cdot \mathrm{m}^{-1} \mathrm{~K}^{-1}$ ]

\section{Daftar Pustaka}

Cittadini, M.; Vanni, M.; Baressi, A. A.; Baldi, G., Simplified procedure for design of catalytic combustors with periodic flow reversal, Chemical Engineering and Processing, 2001, Vol. 40(3), 255-262.

Cittadini, M.; Vanni, M.; Baressi, A. A., Transient behaviour and start-up of periodic flow reversal reactors for catalytic decontamination of waste gases, Chemical Engineering and Processing, 2002, Vol. 41(5), 437-443.

Clearstone Engineering Ltd., http://www.clearstone.ca/services/felm.htm (akses Oktober 2008).

Ibashi, W.; Groppi, G.; Forzatti, P., Kinetic measurements of $\mathrm{CH} 4$ combustion over a 10\% PdO/ZrO2 catalyst using an annular flow microreactor, Catalysis Today, 2003, Vol. 83(1-4), 115-129.

Sapoundjiev, H.; Aube, F., Catalytic flow reversal reactor technology: An Opportunity for heat recovery and greenhouse gas elimination from mine ventilation air, Natural Resources Canada, 1999, www.nrcan.gc.ca 